\title{
A pragmática da interlíngua
}

\begin{abstract}
$\mathrm{s}$ pesquisas em pragmática evoluíram desde seus primórdios apresentando focos teóricos diferentes, fazendo interface com a cognição, com a comunicação e com a gramática formal e, dessa forma, tornando sua definição bastante difícil. Kasper (1996) define a pragmática da interlíngua como o "estudo do conhecimento pragmático na aquisição de segunda língua". O'Keeffe, Clancy e Adolphs (2011) abordam a pragmática como o estudo da interpretação do sentido. Perna, Goldnadel e Molsing (2016), admitem que a pragmática possui uma amplitude fenomenológica que foi, por vezes, considerada indesejável. Nos dias de hoje, entretanto, a pragmática encontra-se em um lugar muito significativo dentro da linguística, por apresentar uma quantidade expressiva de estudos que se encontram em interface externa com a Psicologia Cognitiva e a Antropologia, alem de apresentar conexões estritas na sua interface interna com a Fonologia, Morfologia, Sintaxe e Semântica. A presente edição da Letras de Hoje tem por objetivo mostrar a amplitude da investigação sobre temas relacionados com a aquisição de aspectos pragmáticos no contexto de língua adicional e da L1.

O trabalho de Ibaños e Costa apresenta os aspectos gerais sobre o desenvolvimento da pragmática, desde suas origens e discussões estritamente teóricas, no que concerne as pragmáticas e suas vertentes. Com este foco, os autores iniciam este percurso a partir do período clássico, que se inicia com os filósofos da lógica e da mente, e o concluem com o período contemporâneo, demonstrando que as variações em torno de conceitos de pragmáticas dependem da direção e das interfaces que as diversas pragmáticas perseguem.
\end{abstract}

Strey e Monawar tratam da competência linguísticocomunicativa na sala de aula de língua adicional. Com vistas a dar suporte ao tema, as autoras discutem a modalidade simboulética, um fenômeno da linguagem natural que ocorre na interface entre forma e uso. Primeiramente, apresentam o arcabouço teórico de Kratzer (1981, 1991, 2012) para a modalidade em linguagem natural, além da proposta de Yanovich (2013a, 2013b) para a modalidade simboulética para, em seguida, discutirem as ferramentas da pragmática cognitiva com $\mathrm{o}$ intuito de analisarem o processamento da linguagem, especialmente em relação ao significado procedural e conceitual, baseados na teoria da relevância, de Sperber e Wilson (1995).

Em seu artigo, Corsetti e Perna detalham os resultados de um estudo de marcadores pragmáticos com a metodologia da linguística de córpus. O estudo envolveu análises quantitativas e qualitativas de um pequeno córpus especializado, com a produção oral de aprendizes brasileiros de inglês no nível CEFR B1 e comparações com corpora de referência. Os advérbios mais comuns utilizados para mediar segmentos de discurso, os "hedges" adverbiais explícitos e implícitos utilizados para mitigar atos de fala representativos e as partículas de resposta mínimas utilizadas pelo interlocutor para expressar boa receptividade foram os elementos analisados. Os sujeitos produziram um número limitado de marcadores de discurso e de partículas de resposta.

Cruz e Lopez analisam o comportamento de alunos pré-intermediários de inglês como LE que estão se preparando para a indústria do turismo na fase transacional de um encontro de serviço. Neste contexto específico, eles precisam realizar uma das tarefas para as quais são treinados: dar informações em um centro de visitantes turísticos. Mais especificamente, este estudo analisa (i) as estratégias com as quais eles oferecem informações turísticas, e (ii) como atendem a aspectos relacionais durante $o$ encontro ou gerenciam relacionamento com os turistas através dessas estratégias e as informações fornecidas.

Em seu artigo, Sun procura responder se a transferência positiva de língua existe através dos verbos causativos na Interpretação Simultânea de ChinêsPortuguês, e em que aspectos tal transferência ocorre mais freqüentemente. $\mathrm{O}$ artigo começa fornecendo uma breve discussão sobre a transferência linguística e a construção causativa em chinês e português. Passa à parte metodológica, na qual são transcritos e analisados 10 discursos proferidos por líderes chineses em contextos interculturais e suas interpretações simultâneas. Os resultados mostram que tanto os textos em chinês quanto as interpretações em português apresentam uma alta porcentagem de verbos causativos, e mais da metade dos dados é interpretada através da transferência positiva. Verifica-se que a transferência positiva existe e 
desempenha um papel muito importante na Interpretação Simultânea de Chinês-Português, e a referente estratégia pode ajudar os intérpretes a facilitar o processamento da informação para garantir um melhor desempenho.

Silva, Blanco e Blanco fazem considerações sobre as formas de tratamento, especificamente os pronomes pessoais de tratamento no português do Brasil e no espanhol ibérico, e apresentam teorias que abordam o tema da cortesia. A partir de dados obtidos de duas obras de teatro brasileiras do século XX, analisam e comparam as estratégias pragmáticas desenvolvidas mediante as formas de tratamento, tanto no português do Brasil como no espanhol ibérico. Um segundo objetivo de seu artigo, com motivação didático-pedagógica,foi oferecer aos professores de língua estrangeira algumas apreciações acerca das dificuldades, pragmalinguísticas e sóciopragmáticas que, no processo de aquisição/ aprendizagem das formas de tratamento, podem ocorrer por influência da língua materna.

Semelhantemente, Cohen também se preocupa com as dificuldades trazidas pela distinção entre pragmalinguística e sociopragmática no que tange a aquisição de uma L2 e procura descrever como os professores nativos e não-nativos de inglês como L2 lidam com estas questões pragmáticas na situação de sala de aula. $\mathrm{O}$ autor apresenta uma pesquisa internacional, na qual investigou as experiências de professores de várias línguas com relação ao ensino da pragmática. Em seguida, traz aspectos relacionados ao ensino de pragmática, tais como o background do professor, comparações entre ensino de segunda língua (L2) e língua estrangeira (LE) e o potencial da mídia digital e outros meios para prover modelos de comportamento pragmático.

Andrade e Rauen, por sua vez, apresentam um artigo sobre o ensino e aprendizagem de espanhol como LE. Sua tese é de que o humor facilita o processo e demonstram que a utilização da teoria da relevância auxilia na compreensão de piadas. Como ilustração, analisam três piadas com base na classificação de Yus (2010). Concluem que a aplicação do aparato analítico da teoria da relevância de Sperber e Wilson $(1986,1995)$ permite uma descrição empírica dos processos ostensivoinferenciais necessários para a interpretação de piadas e que as piadas transferíveis têm mais chances de serem compreendidas pelos estudantes, quando comparadas com piadas substituíveis e desafiadoras.

Goldnadel apresenta dois problemas complementares em pragmática: o problema da projeção de pressuposições e o problema da origem das pressuposições. Embora o problema descritivo da projeção tenha recebido maior atenção, não se pode lidar com ele sem assumir algum posicionamento quanto ao problema explanatório, relativo à origem das inferências consideradas pressuposicionais. O desacordo que se observa quanto à descrição da projeção de pressuposições contrasta, no entanto, com um relativo consenso, historicamente construído, sobre a natureza das pressuposições. Segundo esse consenso, pressuposição é fenômeno de natureza convencional, sujeito, apenas em sua projeção, a injunções de ordem conversacional. Mais recentemente, esse consenso tem sido abalado por uma nova onda de trabalhos, que, de diversos modos, passaram a defender a ideia de que pressuposição é fenômeno de natureza fundamentalmente conversacional. $\mathrm{O}$ autor revisita alguns experimentos que avaliam o modo como ocorre o processamento de implicaturas escalares e pressuposições e procura avaliar a importância, no quadro mais geral desse debate, de trabalhos que investiguem o modo como sujeitos em fase de aquisição processam inferências pragmáticas.

Preuss, Rodrigues e Oliveira Júnior expõem os efeitos da instrução explícita sobre enunciados interrogativos totais e asseverativos em espanhol como L2 e suas possíveis interações com variáveis individuais, como a capacidade de atenção, frequência de uso, experiência linguística e docente. Os autores apresentam um estudo quantitativo que abrange testes linguísticos de percepção e produção de enunciados, teste de rede de atenção e questionário de histórico e proficiência linguística. Seu estudo conta com uma amostra de conveniência abrangendo um grupo experimental que recebeu instrução explícita sobre o conteúdo-alvo num período intermediário entre o prée o pós-teste linguístico, e um grupo controle, que não recebeu a instrução. Os resultados mostram que não houve diferença significativa, relacionada ao efeito da instrução.

Siqueira, Duarte Junior, Pereira, Ferrari e Lopes apresentam uma pesquisa experimental na interface com a linguística cognitiva. Os autores conduzem o estudo sobre a compreensão de expressões idiomáticas no desenvolvimento da linguagem em língua portuguesa. Seu artigo tem por objetivo apresentar a aplicação e os resultados de uma tarefa de compreensão de expressões idiomáticas em 270 participantes em três faixas etárias (crianças, adolescentes e adultos). A tarefa é composta por seis itens: sentenças seguidas de uma pergunta aberta e uma pergunta fechada. A comparação das respostas nos três grupos indica um aumento gradual na compreensão de expressões idiomáticas. Além da idade, os autores discutem a implicação das variáveis linguísticas contexto, transparência, metaforicidade e familiaridade na compreensão do fenômeno. As análises sugerem que esse fenômeno complexo deve ser estudado levando em conta todos esses aspectos.

Gostaríamos de parabenizar todos os autores que enriqueceram esta edição da Letras de Hoje com suas contribuições. Esperamos que os tópicos abordados possam estimular novos debates relevantes para os estudos pragmáticos, os quais poderão eventualmente contribuir para a melhoria e o avanço contínuo da linguística.

As Organizadoras 